SCHOOL BELONGING, U.S., CHINA, U.K.

School Psychology International (in press)

Preliminary Investigation of the Psychological Sense of School Membership Scale with Primary School Students in a Cross-Cultural Context

\author{
Rhea Wagle (rhea.wagle@gmail.com) \\ Erin Dowdy (edowdy@ucsb.edu) \\ Chunyan Yang (cyang@education.ucsb.edu) \\ Department of Counseling, Clinical, and School Psychology, \\ University of California, Santa Barbara, Santa Barbara, CA USA 93106 \\ Olympia Palikara (Olympia.Palikara@roehampton.ac.uk) \\ Susana Castro (Susana.Castro@roehampton.ac.uk) \\ School of Education, University of Roehampton, London, SW15 5PJ UK \\ Karen Nylund-Gibson (knylund@education.ucsb.edu) \\ Michael J. Furlong (mfurlong@ucsb.edu) \\ International Center for School Based Youth Development, \\ University of California, Santa Barbara, CA USA 93106
}

Tables: 3

Figures: 1

Word Count: 6787

Corresponding author: Michael Furlong (mfurlong@ucsb.edu)

The research reported here was supported in part by the Institute of Education Sciences, U.S. Department of Education, through Grant \# R305A160157 to the University of California, Santa Barbara. The opinions expressed are those of the authors and do not represent views of the Institute of Education Sciences or the U.S. Department of Education. 
Rhea Wagle, M.Ed., is a doctoral student in the Department of Counseling, Clinical, and School Psychology, University of California Santa Barbara, with an emphasis in school psychology. Rhea's research interests include school-based mental health screening, early identification and intervention, social-emotional learning, and school belonging.

Erin Dowdy, PhD, is a Professor in the Department of Counseling, Clinical, and School Psychology, University of California Santa Barbara. She is a licensed psychologist and a nationally certified school psychologist. Her research career and scholarly publications have focused on behavioral and social emotional assessment, particularly universal screening for social and emotional health and risk. She is the co-principal investigator on several screening measurement projects funded through the Institute of Education Sciences.

Karen Nylund-Gibson, PhD, is an Associate Professor, Gevirtz Graduate School of Education, University of California Santa Barbara. Her research helps to bridge the gap between advanced statistical modeling and applications of these models to educational and psychological issues. She is most interested in mixture modeling, including latent class, latent profile, and latent transition analysis.

Michael Furlong, PhD, is a Distinguished Emeritus Professor and Research Professor, International Center for School Based Youth Development, University of California Santa Barbara. He is a fellow of the American Psychological Association (Division 16, School) and American Educational Research Association and a member of the Society for Study of School Psychology.

Dr. Olympia Palikara is a Senior Lecturer (Associate Professor) in Educational Psychology in the School of Education, University of Roehampton London. Her research interests concern the educational and psychosocial competence of children and adolescents. She is also interested in the effect of primary to secondary school transition on pupils' well-being

Dr. Susana Castro is a Senior Lecturer at Roehampton University London and a Chartered Psychologist (British Psychological Society). Her expertise lies in the areas of atypical development, special education needs and disability, child development and education, with a particular focus on functional approaches to development and disability. She has a track record of international publications and research funding awards in these areas of interest.

Chunyan Yang, PhD, is an Assistant Professor, Department of Counseling, Clinical, and School Psychology, University of California Santa Barbara. Her research interests focus on understanding the functions of school climate, social-emotional learning, school and classroom management techniques, and cultural factors in promoting and prohibiting the development of resilience among children and adolescents, particularly in programs targeting bullying and school engagement. 
SCHOOL BELONGING, United States, CHINA, United Kingdom.

\begin{abstract}
The Psychological Sense of School Membership (PSSM) scale has been used for more than 20 years to measure students' sense of school belonging, yet its psychometric properties have had limited examination with pre-adolescent children. This study investigated the utility and psychometrics of the PSSM in three primary school samples from the United States, China, and the United Kingdom. Exploratory factor analysis revealed good fit for a unidimensional factor structure in the U.S. sample, which was subsequently confirmed in all three samples. Partial invariance across all three samples and full invariance across pairwise samples (United States and United Kingdom; United Kingdom and China) was found. Path analyses revealed significant positive relations of the PSSM total belonging score with gratitude and prosocial behavior, and significant negative relations with symptoms of distress. Future directions and implications are discussed.
\end{abstract}

Keywords: Psychological Sense of School Membership Scale, school belonging, school membership, cross-cultural, primary school age 


\section{Preliminary Investigation of the Psychological Sense of School Membership Scale with Primary School Students in a Cross-Cultural Context}

Research over the past several decades shows that school climate influences students’ psychological and academic well-being. As such, researchers and practitioners have been interested in assessing school climate with the goal of improving student functioning. School climate is conceptualized as a multidimensional construct that includes a school's culture, norms, values, and expectations (National School Climate Council, 2007). The dimensions of school climate have been measured in several ways, including assessing school belonging or psychological sense of school membership (Thapa, Cohen, Guffey, \& Higgins-D’Alessandro, 2013).

This article aims to provide psychometric support for a widely used measure of school belonging — Psychological Sense of School Membership (PSSM; Goodenow, 1993). Although used with adolescent populations, few studies have investigated its use with primary school children (Cheung \& Hui, 2003). Investigating the use of the PSSM with primary school children is particularly important as perceptions of school membership and belonging begin at an early age (Lerner et al., 2018; Whitney \& Smith, 1993) and may differ from adolescents. Additionally, despite its use in cross-national research (e.g., Cowden, Govender, Asante, Reardon, \& George, 2016; Gaete, Montero-Marin, Rojas-Barahona, Olivares, \& Araya, 2016; Ye \& Wallace, 2014), the PSSM has not yet been subject to needed investigations regarding its invariance across sociocultural contexts. This article addresses these limitations by examining the PSSM in primary schools across three countries: the United States, China, and the United Kingdom. This is a first step in a larger cross-national investigation to provide clarity on the use of the PSSM to measure students' sense of school belonging across the world. 


\section{School Belonging: Defining Terms, Relations to Other Constructs, and Assessment}

School belonging has been conceptualized in multiple ways, including "the extent to which students feel personally accepted, respected, included, and supported by others in the school social environment” (Goodenow, 1993, p. 80) and "feel[ing] close to, a part of, and happy at school” (Libbey, 2007, p. 52). Although school belonging is generally defined as feeling accepted by or a part of a school community, the construct of school belonging has also been related to, or used interchangeably with, a number of different terms including school connectedness, student engagement, and school bonding (Furlong, Froh, Muller \& Gonzalez, 2014). The Center for Disease Control (2009) views school connectedness as the "belief by students that adults and peers in the school care about their learning as well as them as individuals” (p. 3). Student engagement is conceptualized by three types of engagement: cognitive, affective, and behavioral (Fredericks, Blumenfeld, \& Paris, 2004). School bonding refers to the connection students feel to their school, school personnel, and academics (Maddox \& Prinz, 2003). These constructs all are related to school belonging as a psychological construct; that is, students' mindsets about how they fit in and are a part of the broader school community.

Regardless of the term, school belonging, engagement, connectedness, and bonding have been linked with academic persistence and effort (Tinto, 1997), better educational outcomes (Goodenow, 1993), prosocial behaviors (Solomon, Battistich, Kim, \& Watson, 1996), fewer mental health problems (Gaete, Rojas-Barahona, Olivares, \& Araya, 2016), reduced bullying victimization (Bosworth, Espelage, \& Simon, 1999), gratitude (Froh, Sefick, \& Emmons, 2008), and lower rates of delinquency and dropout (Finn \& Rock, 1997). Additionally, school belonging has been shown to be a protective factor against high-risk behaviors, including substance use and suicidality (Marraccini \& Brier, 2017). These relations document the developmental advantages 
for students who feel a sense of belonging in their school community.

International studies show that school belonging affects students in similar ways in different cultural contexts. For example, Gaete and colleagues investigated school belonging's relation with mental health problems in students in Chile and found that school belonging was associated with reduced emotional, conduct, hyperactivity, and peer problems (Gaete et al., 2016). Khawaja, Allan, and Schweitzer (2017) found similar results for students in Australia, linking school connectedness to a variety of positive outcomes. These studies, among others, support the findings that school belonging has significant benefits for students,

A substantial body of research has investigated school climate and school belonging with adolescent or early adolescent populations (Cowden et al., 2016; You, Ritchey, Furlong, Shochet, \& Boman, 2011). In contrast, few studies have examined the effects of school belonging on younger children in primary schools. Academic habits and social learning begin in primary school, lending support to the idea that interventions fostering school belonging in the primary grades could have profoundly positive consequences. Students at this age are beginning to view themselves as part of the educational institution and as people who belong to a school. In addition, primary school students generally stay with one teacher throughout the school day, implicating teacher support as particularly influential at this developmental stage. It is during this early developmental period that students begin to form life-long mindsets related to school experiences, such as their identity as a "student,” a "learner," and a “citizen” of a school community (Lerner et al., 2018). For these reasons, further investigation of school belonging among primary school students, including validated measures for this age group, is needed.

\section{Psychological Sense of School Membership (PSSM) Scale}

Goodenow (1993) created a scale designed to measure adolescents’ sense of school 
membership or belonging, which has been widely used across a variety of contexts. The PSSM includes 18 items (13 positively and five negatively worded items) measured on a five-point Likert-type scale $(1=$ not at all true and $5=$ completely true $)$. The items were initially validated on one suburban and two urban populations and were found to be positively correlated with academic success and motivation (Goodenow, 1993). Other studies have found that the PSSM is negatively correlated with emotional distress and behavioral problems (Shochet, Dadds, Ham \& Montague, 2006).

Although Goodenow originally described the scale as one-dimensional, solely measuring the construct of school belonging, the scale's dimensionality was not investigated during the initial study. Subsequent studies have found varying factor structures across different samples, particularly with the five negatively worded items. Several studies found that the negatively worded items formed their own factor (Gaete et al., 2016; Hagborg, 1994; Ye \& Wallace, 2014; You et al., 2011), which may be due to a method effect (DiStefano \& Motl, 2009). Two of these studies also found that the scale had a three-factor structure, but, depending on the specific study, some items were not retained due to cross-loadings (e.g., Hagborg, 1994; You et al., 2011). Gaete and colleagues (2016) provided evidence that a one-factor solution was possible after removing the negatively worded items, which had strong cross-loadings. Similarly, O’Farrell and Morrison (2003) found a unidimensional structure after removing 13 of the 18 items, which were found to have cross-loadings. These studies involving adolescent samples provide evidence that there is ambiguity surrounding the factor structure and necessity of including all 18 PSSM items.

Few studies have examined the PSSM’s factor structure with primary school children. In one previous, independent study, Cheung and Hui (2003) translated the PSSM into Chinese and modified the response scale to a six-item response scale for use with students in primary school. 
A principal components analysis provided evidence for a two-factor structure, with 13 positively worded items forming a school belonging factor and the five negatively worded items forming a feeling of rejection factor. No other studies were found that used confirmatory factor analysis to confirm the factor structure of the PSSM.

\section{Current Study}

The current study investigated the factor structure of the PSSM using three primary school samples: (a) United States, (b) China, and (c) United Kingdom. These samples were chosen to provide information that could better inform future studies involving cross-cultural and cross-national samples. Due to the inconsistencies of the factor structure of the PSSM in past studies and the lack of investigation in primary schools, this study examined the factor structure of the PSSM on primary school populations in cross-cultural contexts.

Since several previous studies found that the negatively worded PSSM items converge on a separate factor, we examined the possible contribution of negatively worded items for primary school age children. Ye and Wallace (2014) proposed that the negatively worded items form a unique factor, but fundamentally as a method artifact. This contrasts with the original PSSM formulation that included negatively worded items because, for Goodenow (1993), acceptance and rejection were considered to be opposite ends of a school belonging continuum — if an individual does not feel accepted, they must feel rejected and vice versa. An alternative conceptualization is provided by peer relationship studies that suggest acceptance and rejection are distinct, but related constructs (Bukowski, Sippola, Hoza, \& Newcomb, 2000). Bukowski et al. (2000) states that "acceptance refers to the number of strong positive links a child has with other members of the group; rejection refers to the number of negative links a child has with members of the group” (p. 12). Hence, while these two constructs are interrelated, they might not 
be polar opposites. Consequently, it is not expected that negatively and positively worded PSSM items would load onto one factor, even if items were reverse coded.

The literature on school belonging is muddled and it is unclear if it is one continuum with acceptance and rejection on opposite ends of the continuum, or whether two separate continua of acceptance and rejection form the construct. This study investigated the psychometric properties of the PSSM in cross-cultural primary school populations to examine its factor structure and further clarify this construct of school belonging in the crucial developmental context of primary school. In addition, this study examined whether a subset of items could efficiently measure primary school students’ perceptions of school belonging to support research and educational practices in primary school populations across the world.

\section{Method}

\section{Participants}

All students were between the ages of eight and thirteen. Mean ages are as follows: United States $=10.23(S D=0.87)$, China $=10.38(S D=1.05)$, United Kingdom $=9.19,(S D=$ 1.00).

The U.S. sample consisted of 782 primary school students aged eight (0.1\%), nine (22\%), ten (37.8\%), eleven (35.5\%), twelve (2.9\%), and thirteen (0.8\%) from seven schools in a small urban school district in California. The sample was made up of 50.8\% female and $49.0 \%$ male students. At home, the majority of the sample spoke English (71.5\%). Other students spoke Spanish (6.9\%), English and Spanish (15.8\%), or another language (5.8\%) at home. All students were proficient English speakers and were able to read and respond to survey questions. The ethnicity breakdown, as reported by students, is: Caucasian/White (40.5\%), Hispanic/Latino/a/Mexican (21.6\%), Native American or American Indian (8.6\%), Asian 
American (5.4\%), Black or African American (2.7\%), Pacific Islander (1.3\%), Other ethnicity (16\%), missing response (3.9\%).

The Chinese sample consisted of 1,178 students aged eight (1.1\%), nine (19.1\%), ten (33.1\%), eleven (33.5\%), twelve (11\%), and thirteen (1.3\%), from five schools in Changsha and Yongzhou, Hunan Provinces in China. This sample included both suburban and urban school districts. The sample consisted of $60.5 \%$ male students and $39.5 \%$ female students.

The U.K. sample consisted of 522 students aged eight (30.8\%), nine (30.5\%), ten (27.2\%) and eleven (11.5\%), from three primary schools in an urban area of London. The sample was made up of $48.7 \%$ male and $51.3 \%$ female students. About half (51\%) of the students spoke English at home, with the remaining students indicating that they spoke another language at home, including Hindi, Arabic, and Polish. All students were proficient English speakers and were able to read and respond to survey questions.

\section{Procedure}

Researchers across the three countries discussed the need for a measure of school belonging in primary schools. Following a literature review and discussions regarding instruments for use in the various contexts, the researchers decided to embark on a cross-national study to examine the PSSM. The researchers initially determined the desire for a unidimensional, brief, and efficient measure of school belonging, which was consistent with Goodenow’s originally stated rationale for the PSSM.

The participating school sites were part of a convenience sample based on the researchers' connections with different schools. For the U.S. and U.K. samples, the survey was administered in English. For the Chinese sample, the PSSM was translated into simplified Chinese by two researchers and independently back translated into English by two other 
researchers. All four researchers were fluent in English and Chinese. Further, four teachers from elementary schools in China reviewed the Chinese version to evaluate its readability for elementary school students; they confirmed the readability and no additional modifications were made.

Local policies and procedures related to consent for surveys were followed. The U.S. sample required active consent procedures, while the Chinese and U.K. samples allowed passive consent procedures. The procedures for each country are described in the Online Supplementary Materials.

\section{Instruments}

\section{Psychological Sense of School Membership (PSSM)}

The PSSM (Goodenow, 1993) was the focal instrument for this study. Two modifications were made to the scale to be more developmentally appropriate for the younger students in this study. First, the original five-point response scale was modified to a simplified six-point response scale in a yes/no format $(1=$ no, never, $2=$ no, almost never, $3=$ yes, sometimes, $4=$ yes, often, 5 = yes, very often, and 6 = yes, always) to reduce the cognitive burden for primary school students. This modification is consistent with another PSSM study which also used a sixpoint response scale for primary school students (Cheung \& Hui, 2003). Second, the items were modified into question form rather than the original statement form. Questions as opposed to statements are considered more developmentally appropriate (Woolfolk, 2004). Most of the PSSM item content remained unchanged: (e.g., original item = "People at this school are friendly to me”; modified item = “Are people at this school friendly to you?”). However, two of the originally negatively worded items were converted into positive wording after the modification: (original item = “Sometimes I don’t feel as if I belong here”; modified item = "Do you belong at 
your school?”; original item = “Teachers here are not interested in people like me”; modified item $=$ “Are teachers interested in students like you?”). These items were changed to avoid a double negative thought process (e.g.: “Do you feel as if you don’t belong at your school?”). Thus, the survey used in this study consisted of 15 positively worded and three negatively worded questions.

In summary, all 18 items were modified to a question format and the response scale was changed to match the question format. The modifications were originally conducted in English. The survey was then translated into simplified Chinese and back translated into English. The Online Supplementary Material Included the English and Chinese PSSM items.

\section{Convergent Validity Instruments}

See Online Supplementary Materials for additional details.

Social and Emotional Health Survey - Primary (SEHS-P). Four gratitude items and four prosocial items from the SEHS-P (Furlong, You, Renshaw, O’Malley, \& Rebelez, 2013) were used to assess convergent validity because of school belonging's positive associations with gratitude (Froh et al., 2008) and prosocial behavior (Solomon et al., 1996). The items used the same six-point response scale as the PSSM. The internal consistency across the three samples were: gratitude ( $\alpha=.68-.69)$ and prosocial behavior $(\alpha=.80-.82)$.

Me and My School Questionnaire (M\&MS). For the U.S. and U.K. samples, the M\&MS (Deighton et al., 2013) was used as a measure of divergent validity as school belonging has been found to be inversely related to distress. The M\&MS has 16 items that assess emotional and behavioral difficulties and uses a three-point response format: never, sometimes, always. For this study, the alpha internal consistency for the total score for U.S. and U.K. samples were .76 and .77 , respectively. 
Strengths and Difficulties Questionnaire (SDQ). For the Chinese sample, the SDQ total difficulties score was used as a measure of divergent validity as a measure of psychological distress (Goodman, 1997). The SDQ uses a three-item response scale: not true, somewhat true, certainly true. The alpha internal consistency for the SDQ total difficulties score was .84.

\section{Statistical Analyses}

Prior to investigating the factor structure, assumptions of normality were tested by analyzing Q-Q plots, boxplots, and descriptive statistics (see Table 1). The same item in the U.S. and U.K. samples (16. Do you wish you were in a different school?) and one item in the Chinese sample (17. Are you proud to be a part of your school?) displayed high skewness and kurtosis values (acceptable skewness and kurtosis values are between -3.0 and +3.0; Tabachnick \& Fidel, 2012). These items were included in the analysis using maximum likelihood with robust standard errors, which helps minimize standard errors. All other items met assumptions.

Next, the U.S. sample was split in half and an exploratory factor analysis (EFA) of all 18 items was conducted using Mplus 6.1 (Muthén \& Muthén, 2010). Analyses were first conducted on the U.S. sample given that the PSSM was originally developed in the United States and the interest was to see if this model would fit well with other cultures. Given the lack of literature regarding the psychometrics of the PSSM in primary schools, an EFA was conducted on the first randomly generated split sample. An oblique Geomin rotation was chosen to find a simple solution due to the fact that the survey items are similar and may correlate with one another, which is common in psychological research (Fabrigar, Wegener, MacCallum, \& Straham, 1999). Then, a confirmatory factor analysis (CFA) was run on the other half of the U.S. sample, the Chinese sample, and the U.K. sample to confirm the factor solution found in the EFA.

Next, measurement invariance tests across all three samples were completed to evaluate 
if the solution found for the U.S. sample was replicated in the U.K. and Chinese samples. Establishing measurement invariance involves fitting a series of CFA models, each with different levels of invariance and comparing model fit of the models (Meredith, 1993). The first step is configural invariance to ensure that the factor model fits each group independently. Next, item loadings are constrained to be equal across groups while all other model parameters are free. Then, item intercepts and loadings are fixed to test for scalar invariance. Scalar invariance is an important step in measurement invariance testing; if it holds, latent mean comparisons can be made. Nested models are compared using chi-square difference test ( $\Delta \chi^{2}$; Chen, 2007), in addition to the change in CFI $(\triangle \mathrm{CFI})$ and change in RMSEA, where values of $\Delta \mathrm{CFI} \leq .01$ and $\Delta$ RMSEA $\leq .015$ support invariance (Chen, 2007; Cheung \& Rensvold, 2002). Lastly, path analyses to examine convergent and discriminant validity using positive and negative mental health indicators were conducted using items from the SEHS-P, M\&MS, and SDQ.

\section{Results}

\section{Exploratory and Confirmatory Factor Analyses}

With the goal of a brief measure with a unidimensional factor structure, a series of EFAs were run on the first U.S. randomly generated split sample, followed by CFAs separately for the split samples U.S., Chinese, and the U.K. The first EFA was run with all 18 items and then subsequent EFAs were run following item deletion based on Howard's (2016) method: items that loaded onto primary factors at .40 and above were retained, given that they did not load onto any alternate factors above .30 and that the difference between the primary and alternate factor loadings was at least .20. All other items were deleted.

Model fit criteria was based on Hu and Bentler (1999) who state that CFI values above .95 indicate good fit and values above .90 indicate adequate fit. Similarly, Browne and Cudeck 
(1989) found that RMSEA and SRMR values less than .05 suggest good fit and values up to .08 suggest reasonable fit. Using these parameters and the Howard (2016) method for item deletion, the iterative EFA process resulted in item deletion of seven items with cross-loadings or low factor loadings, one item which had repetitive wording to another item, and one remaining negatively worded item for a total of nine items deleted (see Online Supplementary Material for information about how the number of factors was determined).

A final EFA was completed using the remaining nine items, which produced a one-factor solution that had good fit, $\chi^{2}(27)=71.55, p<.01$; RMSEA $=.06$, SRMR $=.04$, CFI $=.95 . \mathrm{A}$ CFA was conducted on the second split portion of the U.S. sample and confirmed that the remaining nine items fit well onto a one-factor solution, $\chi^{2}(27)=74.22, p<.01$; $\mathrm{RMSEA}=.07$, SRMR $=.03, \mathrm{CFI}=.96$, indicating that the nine items measured a unidimensional latent trait. Factor loadings remained strong $(\lambda=.52-.79$; see Table 2$)$. Additionally, for the final model, eigenvalues were greater than one and parallel analysis indicated a one-factor solution. Lastly, CFAs were performed to examine if the final U.S. sample factor structure fit for the Chinese and U.K. samples. Analyses indicated good fit and high factor loadings (Chinese sample: $\chi^{2}(27)=$ 231.67, $p<.01 ; \mathrm{RMSEA}=.08, \mathrm{SRMR}=.04, \mathrm{CFI}=.94 ; \mathrm{U} . \mathrm{K} .: \chi^{2}(27)=65.37, p<.01 ; \mathrm{RMSEA}=$ $.05, \mathrm{SRMR}=.03, \mathrm{CFI}=.99$; see Table 2 for factor loadings).

\section{Factorial Invariance}

Measurement invariance testing was conducted in three steps: configural, metric, and scalar. Configural invariance analysis revealed good model fit (i.e., RMSEA $=.07$, SRMR $=.04$, CFI = .96), supporting configural invariance across the U.S., Chinese, and U.K. samples. Next, metric invariance was tested and confirmed $(\triangle \mathrm{CFI}<.01, \triangle \mathrm{RMSEA}<.015)$, indicating that the constraints did not lead to a meaningful change in fit between Model 2 and Model 1 and 
providing support for metric invariance across all three countries. Lastly, scalar invariance was tested. Fit indexes, $\triangle \mathrm{CFI}$, and $\triangle \mathrm{RMSEA}$ indicated that there were meaningful changes between Model 3 and Model 2 and that full invariance across all three countries could not be achieved. Since there was evidence of metric invariance across all three countries, the countries were then tested for scalar invariance pairwise. Pairwise scalar invariance analyses revealed scalar invariance between the U.S. and U.K. samples $(\triangle \mathrm{RMSEA}<.015)$, as well as between Chinese and U.K. samples $(\triangle \mathrm{CFI}<.01, \Delta \mathrm{RMSEA}<.015)$. While the delta CFI value $(\Delta \mathrm{CFI}=.016)$ for the U.S. and U.K. pair was slightly larger than the desired value of .01 for invariance, the delta RMSEA indicated invariance, and, therefore, full invariance was assumed. Scalar invariance between the U.S. and Chinese samples was not confirmed $(\Delta \mathrm{CFI}>.01, \Delta \mathrm{RMSEA}>.015)$. These analyses provide evidence of partial measurement invariance across all three samples and full measurement invariance across two of the three pairs of countries (i.e., United States and United Kingdom; China and United Kingdom). The analyses also suggest that the modified PSSM construct differed in the U.S. and Chinese samples. Model fit indexes can be seen in Table 3.

\section{Additional Psychometric Analyses}

Reliability and validity checks were performed for the final nine items of the PSSM separately in all three samples: U.S. sample ( $\alpha=.87$ ), Chinese sample ( $\alpha=.85$ ), U.K. sample ( $\alpha=.83$ ). These results support high internal consistency for the final version of the PSSM.

To examine convergent and discriminant validity, path analyses were conducted using positive (gratitude and prosocial behavior) and negative (internal and external distress) mental health indicators. The path analyses revealed significant positive relations of the PSSM total belonging score with the SEHS-P gratitude mean score and prosocial mean score, and significant negative relations with the M\&MS mean score and SDQ total difficulties mean score. All models 
had adequate fit to the data (see Figure 1).

\section{Discussion}

This study investigated the factor structure of the PSSM on primary school populations and examined measurement invariance for three cross-cultural groups. Results of this study were similar to previous studies with adolescent students (Gaete et al., 2016; Hagborg, 1994; Ye \& Wallace, 2014; You et al., 2011) and supported previous research, which showed that a reduced number of PSSM items can be used to measure students' sense of school belonging. Some may raise questions about whether this is a new instrument; however, this was not our intent. Rather, the intent was to find an efficient tool that can be used to measure primary students' sense of school belonging across different cultures. The findings from this study are consistent with Goodenow’s (1993) original objective of creating a unidimensional measure of school belonging. Exploratory factor analyses concluded that several items had cross-loadings and low factor loadings. Following systematic item deletion, the remaining positively worded items formed a nine-item unidimensional measure for school belonging. CFAs revealed good model fit for all three populations. Measurement invariance analyses confirmed partial invariance across the U.S., Chinese, and U.K. samples, as well as full invariance across two pairs of countries: United States and United Kingdom, and United Kingdom and China. Path analyses provided evidence for convergent and discriminant validity of the PSSM.

School personnel in each of these countries (i.e., United States, China) may consider using this nine-item PSSM measure to analyze school belonging for primary school populations. However, additional research is needed prior to recommending this tool be used to compare students' sense of school belonging internationally. The measurement invariance results reveal that there are were some differences in how the school belonging construct is being measured 
across all three countries. These differences might be due to cultural variations in the conceptualization of school belonging or other procedural variations such as survey format (online vs. paper). The reasons for the differences are beyond the scope of this study and may benefit from additional analyses in future research. However, the results of pairwise scalar invariance across the U.S. and U.K. samples, and across the U.K. and Chinese samples show promising results that a cross-national measure of school belonging for primary school students may be possible following additional research exploring the cross-cultural differences in school belonging.

The original content of the PSSM included some items that focused on students' sense of rejection. These items have not held up well in subsequent analyses, and have often formed a second factor. If the literature on peer relationships and the information on the method effects of negatively worded items are considered, school belonging should be a positive construct of belonging to a school in terms of peer relationships, teacher relationships, and the larger school community. Rejection may need to be considered separately when measuring for school belonging through the use of a rejection measure (e.g., Social Peer Rejection Measure; LevWiesel, Sarid, \& Sternberg, 2012). The results of this study suggest that the negatively worded items on the PSSM measure a separate construct than do the positively worded items. Thus, the PSSM may benefit from only including positively worded items, as seen in this study.

This study contains limitations with respect to the structural and external validity evidence, and also provides insight into areas for future needed research. Although measurement invariance analyses were conducted across the different countries, there is no knowledge about invariance across different ages, ethnicities, and genders. It should also be noted that modifications of the measure were made. Although these modifications appeared to be 
developmentally appropriate, further analysis would be beneficial in order to confirm that the modifications work well with additional primary school populations. Additionally, with respect to the procedures, the U.S. sample used an online survey format, while the U.K. and Chinese samples used a paper administration format. This difference may have influenced measurement invariance results, such that the U.S. sample had more differences with the Chinese samples than with U.K. sample. Further, due to the fact that the delta CFI value for the U.S. and U.K. pair was slightly large, future studies should also validate if there is indeed full invariance between the two countries. Finally, the measure of emotional distress used in the path analyses differed for the Chinese sample, which may have affected the path analyses and, subsequently, the discriminant validity analysis of the measure. Further research is needed to explore the role of rejection in students’ perceptions of belonging at school and analyze whether the construct of school belonging is unidimensional or multidimensional.

School belonging's many influences on academics, mental health, and overall well-being of students make it a critical construct for investigation (Bosworth et al., 1999; Finn \& Rock, 1997; Gaete et al., 2016). As such, valid and appropriate measures of school belonging are necessary for all age groups, including primary school students. This study provided a preliminary investigation of a version of the PSSM modified for use with primary school students that was found to have high internal consistency and strong convergent and divergent validity evidence. This measure also had invariance across multiple national samples, providing support for further exploring its use in a variety of contexts across the world. 


\section{References}

Bosworth, K., Espelage, D. L., \& Simon, T. R. (1999). Factors associated with bullying behavior in middle school students. The Journal of Early Adolescence, 19, 341-362. doi:10.1177/0272431699019003003

Browne, M. W., \& Cudeck, R. (1989). Single sample cross-validation indices for covariance structures. Multivariate Behavioral Research, 24, 445-455.

Bukowski, W. M., Sippola, L., Hoza, B., \& Newcomb, A. F. (2007). Pages from a sociometric notebook: An analysis of nomination and rating scale measures of acceptance, rejection, and social preference. New Directions for Child and Adolescent Development, 2000 (88), 11-26. doi:10.1002/cd.23220008804

Centers for Disease Control and Prevention. (2009). School connectedness: Strategies for increasing protective factors among youth. Atlanta, GA: U.S. Department of Health and Human Services.

Chen, F. F. (2007). Sensitivity of goodness of fit indexes to lack of measurement invariance. Structural Equation Modeling: A Multidisciplinary Journal, 14, 464-504. doi.org/10.1080/10705510701301834

Cheung, G. W., \& Rensvold, R. B. (2002). Evaluating goodness-of-fit indexes for testing measurement invariance. Structural Equation Modeling, 9, 233-255. doi:10.1207/S15328007SEM0902_5

Cheung, H. Y., \& Hui, S. K. F. (2003). Mainland immigrant and Hong Kong local students' psychological sense of school membership. Asia Pacific Education Review, 4, 67-74. doi:10.1007/bf03025553

Cowden, R. G., Govender, K., Asante, K. O., Reardon, C., \& George, G. (2016). Validation of 
the perceived sense of school membership scale. Journal of Psychoeducational Assessment, 15, 1-7. doi:10.1177/0734282916678495

Deighton, J., Tymms, P., Vostanis, P., Belsky, J., Fonagy, P., Brown, A., ...Wolpert, M. (2013). The development of a school-based measure of child mental health. Journal of Psychoeducational Assessment, 31, 247-257. doi:10.1177/0734282912465570

DiStefano, C., \& Motl, R. (2009). Further investigation method effects associated with negatively worded items on self-report surveys. Structural Equation Modeling: A Multidisciplinary Journal, 13, 440-464. doi:10.1207/s15328007sem1303_6

Fabrigar, L. R., Wegener, D. T., MacCallum, R. C., \& Strahan, E. J. (1999). Evaluating the use of exploratory factor analysis in psychological research. Psychological Methods, 3, 272299. doi:10.1037/1082-989X.4.3.272

Finn, J. D., \& Rock, D. A. (1997). Academic success among students at risk for school failure. Journal of Applied Psychology, 82, 221-234. doi:0021-9010/97/

Fredericks, J. A., Blumenfeld, P. C., \& Paris, A. H. (2004). School engagement: Potential of the concept, state of the evidence. Review of Educational Research, 74, 59-109. doi:10.3102/00346543074001059

Froh, J. J., Sefick, W. J., \& Emons, R. A. (2008). Counting blessings in early adolescents: An experimental study of gratitude and subjective well-being. Journal of School Psychology, 46, 213-233. doi:10.1016/j.jsp.2007.03.005 
Furlong, M. J., Froh, J., Muller, M., \& Gonzalez, V. (2014). The role of student engagement in engaged living and psychological and social well-being: The centrality of connectedness/relatedness. In D. J. Shernoff \& J. Bempechat (Eds.), National Society for the Study of Education Yearbook—Engaging youth in schools: Empirically-based models to guide future innovations. New York, NY: Columbia Teachers College.

Furlong, M. J., You, S., Renshaw, T. L., O’Malley, M. D., \& Rebelez, J. (2013). Preliminary development of the Positive Experiences at School Scale for elementary school children. Child Indicators Research, 6, 753-775. doi:10.1007/s12187-013-9193-7

Gaete, J., Montero-Marin, J., Rojas-Barahona, C. A., Olivares, E., \& Araya, R. (2016). Validation of the Spanish version of the Psychological Sense of School Membership (PSSM) scale in Chilean adolescents and its association with school-related outcomes and substance use. Frontiers in Psychology, 7, 1-11. doi:10.3389/fpsyg.2016.01901

Goodenow, C. (1993). The psychological sense of school membership among adolescents: Scale development and educational correlates. Psychology in the Schools, 30, 79-90. doi:10.1002/1520-6807(199301)30:1

Goodman, R. (1997). The Strengths and Difficulties Questionnaire: A research note. Child Psychology \& Psychiatry \& Allied Disciplines, 38, 581-586. doi:10.1111/j.14697610.1997.tb01545.x

Hagborg, W. J. (1994). An exploration of school membership among middle- and high-school students. Journal of Psychoeducational Assessment, 12, 312-323. doi:10.1177/073428299401200401

Howard, M. C. (2016). A review of exploratory factor analysis decisions and overview of current practices: What are we doing and how can we improve? International Journal of Human- 
Computer Interaction, 32, 51-62. doi:10.1080/10447318.2015.1087664

Hu, L., \& Bentler, P. M. (1999). Cutoff criteria for fit indexes in covariance structure analysis: Conventional criteria versus new alternatives. Structural Equation Modeling: A Multidisciplinary Journal, 6, 1-55. doi:10.1080/107055199095400118

Khawaja, N. G., Allan, E., \& Schweitzer, R. D. (2017). The role of school connectedness and social support in the acculturation in culturally and linguistically diverse youth in Australia. Australian Psychologist. First published online:13 October 2017. doi:10.1111/ap.12327

Lerner, R. M., Lerner, J. V., Geldhof, G. J., Gestsdóttir, S., King, P. E., Sim, A. T., ... Dowling, E. (2018). Studying positive youth development. In J. E. Lansford \& P. Banati. (Eds.), Handbook of adolescent development research and its impact on global policy (pp. 6882). New York, NY: Oxford University Press.

Lev-Wiesel, R., Sarid, M., \& Sternberg, R. (2012). Measuring social peer rejection during childhood: Development and validation. Journal of Aggression, Maltreatment, and Trauma, 22, 482-492. doi:10.1080/10926771.2013.785456

Libbey, H. P. (2007). School connectedness: Influence above and beyond family connectedness. United States: UMI. Available online: www.cpc.unc.edu/projects/addhealth/publications/database/4145

Maddox, S. J., \& Prinz, R. J. (2003). School bonding in children and adolescents: Conceptualization, assessment, and associated variables. Clinical Child and Family Psychology Review, 6, 31-49. doi:1096-4037/03/0300-0031/0

Marraccini, M. E., \& Brier, Z. M. (2017). School connectedness and suicidal thoughts and behaviors: A systematic meta-analysis. School Psychology Quarterly, 32, 5-21. 
doi:10.1037/spq0000192

Muthén, L. K., \& Muthén, B. O. (1998-2013). Mplus user's guide (6 ${ }^{\text {th }}$ ed.). Los Angeles, CA: Muthén \& Muthén.

O’Farrell, S. L., \& Morrison, G. M. (2003). A factor analysis exploring school bonding and related constructs among upper elementary students. The California School Psychologist, 8, 53-72. doi:10.1007/BF03340896

Shochet, I., Dadds, M., Ham, D., \& Montague, R. (2006). School connectedness is an underemphasized parameter in adolescent mental health: Results of a community prediction study. Journal of Clinical Child \& Adolescent Psychology, 35, 170-179. doi:10.1207/s15374424jccp35

Solomon, D., Battisch, V., Kim, D., \& Watson, M. (1996). Teacher practices associated with students' sense of classroom as a community. Social Psychology of Education, 1, 235267. doi:10.1007/BF02339892

Tabachnik, B. G., \& Fidel, L. S. (2012). Using multivariate statistics (6 ${ }^{\text {th }}$ ed.). Boston, MA: Pearson.

Thapa, A., Cohen, J., Guffey, S., \& Higgins-D’Alessandro, A. (2013). A review of school climate research. Review of Educational Research, 83, 357-385. doi:10.3102/0034654313483907

Tinto, V. (1997). Classrooms as communities: Exploring the educational character of student persistence. The Journal of Higher Education, 68, 599-623. doi:10.2307/2959965

Whitney, I., \& Smith, P. K. (1993). A survey of the nature and extent of bullying in junior/middle and secondary schools. Educational Research, 35, 3-25. doi:10.1080/0013188930350101 
Woolfolk, A. (2004). Educational psychology (9 $9^{\text {th }}$ ed.) Boston, MA: Allyn \& Bacon.

Ye, F., \& Wallace, T. L. (2014). Psychological Sense of School Membership Scale: Method effects associated with negatively worded items. Journal of Psychoeducational Assessment, 32, 202-215. doi:10.1177/0734282913504816

You, S., Ritchey, K., Furlong, M. J., Shochet, I., \& Boman, P. (2011). Examination of the latent structure of the Psychological Sense of School Membership Scale. Journal of Psychoeducational Assessment, 29, 225-237. doi:10.1177/0734282910379968 
Table 1

Descriptive Statistics for Retained PSSM Items for the U.S., Chinese, and U.K. Samples

\begin{tabular}{|c|c|c|c|c|}
\hline PSSM Question & Sample & $M(S D)$ & Skewness (SE) & Kurtosis $(S E)$ \\
\hline \multicolumn{5}{|c|}{ 1. Do you feel like you are a real part of your school? } \\
\hline & U.S. & $4.61(1.43)$ & $-0.72(.09)$ & $-0.56(.18)$ \\
\hline & Chinese & $4.62(1.54)$ & $-0.72(.07)$ & $-0.64(.14)$ \\
\hline & U.K. & $4.82(1.42)$ & $-0.94(.11)$ & $-0.28(.22)$ \\
\hline \multicolumn{5}{|c|}{ 5. Are most teachers at your school interested in you? } \\
\hline & U.S. & $4.19(1.32)$ & $-0.27(.09)$ & $-0.69(.18)$ \\
\hline & Chinese & $3.17(1.44)$ & $0.33(.07)$ & $-0.55(.14)$ \\
\hline & U.K. & $3.94(1.39)$ & $0.07(.11)$ & $-0.91(.22)$ \\
\hline \multicolumn{5}{|c|}{ 6. Do you belong at your school? } \\
\hline & U.S. & $5.12(1.25)$ & $-1.38(.09)$ & $1.12(.18)$ \\
\hline & Chinese & $4.19(1.74)$ & $-0.43(.07)$ & $-1.13(.14)$ \\
\hline & U.K. & $5.06(1.45)$ & $-.1 .36(.11)$ & $0.64(.22)$ \\
\hline \multicolumn{5}{|c|}{$\begin{array}{l}\text { 7. Is there a teacher or other adult at school that you } \\
\text { can talk to if you have a problem? }\end{array}$} \\
\hline & U.S. & $4.84(1.44)$ & $-0.99(.09)$ & $-0.18(.18)$ \\
\hline & Chinese & $3.02(1.69)$ & $0.46(.07)$ & $-0.92(.14)$ \\
\hline & U.K. & $5.01(1.48)$ & $-1.19(.11)$ & $0.46(.22)$ \\
\hline \multicolumn{5}{|c|}{ 8. Are people at school friendly to you? } \\
\hline & U.S. & $4.84(1.14)$ & $-0.72(.09)$ & $-0.40(.18)$ \\
\hline & Chinese & $4.23(1.42)$ & $-0.23(.07)$ & $-0.89(.14)$ \\
\hline & U.K. & $4.70(1.35)$ & $-0.72(.11)$ & $-0.53(.22)$ \\
\hline \multicolumn{5}{|c|}{ 10. Are you included in a lot of school activities? } \\
\hline & U.S. & $4.60(1.32)$ & $-0.69(.09)$ & $-0.47(.18)$ \\
\hline & Chinese & $3.51(1.71)$ & $0.18(.07)$ & $-1.19(.14)$ \\
\hline & U.K. & $4.37(1.48)$ & $-0.41(.11)$ & $-1.00(.22)$ \\
\hline \multicolumn{5}{|c|}{ 11. Are you treated with as much respect as other students? } \\
\hline & U.S. & $4.72(1.33)$ & $-0.83(.09)$ & $0.16(.18)$ \\
\hline & Chinese & $3.76(1.66)$ & $-0.06(.07)$ & $-1.11(.14)$ \\
\hline & U.K. & $4.41(1.56)$ & $-0.51(.11)$ & $-0.89(.22)$ \\
\hline \multicolumn{5}{|c|}{ 13. Can you be yourself at school? } \\
\hline & U.S. & $4.84(1.40)$ & $-1.03(.09)$ & $0.04(.18)$ \\
\hline & Chinese & $4.44(1.65)$ & $-0.65(.07)$ & $-0.82(.14)$ \\
\hline & U.K. & $4.76(1.56)$ & $-0.99(.11)$ & $-0.26(.22)$ \\
\hline \multicolumn{5}{|c|}{ 17. Are you proud to be a part of your school? } \\
\hline & U.S. & $4.87(1.34)$ & $-0.92(.09)$ & $0.27(.18)$ \\
\hline & Chinese & $3.81(1.84)$ & $-0.14(.07)$ & $-1.37(.14)$ \\
\hline & U.K. & $5.14(1.34)$ & $-1.39(.11)$ & $0.75(.22)$ \\
\hline
\end{tabular}

Note. The minimum and maximum responses for each item for 1 and 6, respectively, for all three samples. See Online Supplemental Material for a list of all 18 PSSM items. 
Table 2

Factor Loadings for Exploratory and Confirmatory Factor Analyses for Each Sample with Geomin Rotation for One-Factor Solution

\begin{tabular}{lrrrr}
\hline & \multicolumn{4}{c}{ Samples } \\
\cline { 2 - 5 } & U.S. & U.S. & Chinese & U.K. \\
& EFA & CFA & CFA & CFA \\
\hline 1. Do you feel like you are a real part of your school? & .79 & .78 & .64 & .79 \\
5. Are most teachers in your school interested in you? & .51 & .60 & .55 & .78 \\
6. Do you belong at your school? & .77 & .79 & .69 & .62 \\
7. Is there a teacher or some other adult at school that you can talk & & & & \\
to if you have a problem? & .52 & .52 & .48 & .89 \\
8. Are people at school friendly to you? & .68 & .66 & .62 & .84 \\
10. Are you included in a lot of school activities? & .64 & .54 & .63 & .60 \\
11. Are you treated with as much respect as other students? & .58 & .58 & .69 & .71 \\
13. Can you be yourself at school? & .61 & .64 & .61 & .64 \\
17. Are you proud to be a part of your school? & .75 & .79 & .66 & .90 \\
\hline
\end{tabular}

Note. All loadings are significant at the $p<.05$ level. See Online Supplemental Material for a list of all 18 PSSM items. 
SCHOOL BELONGING, United States, CHINA, United Kingdom.

Table 3

Model Fit Indices for Measurement Invariance

\begin{tabular}{lcccccccccc}
\hline Invariance tests & $\chi^{2}$ & $d f$ & $\Delta \chi^{2}$ & $\Delta d f$ & RMSEA (90\% CI) & SRMR & CFI & $\Delta$ CFI & $\Delta$ RMSEA \\
\hline Configural & $436.102(p<.001)$ & 81 & - & - & $.074(.067, .080)$ & 0.035 & 0.958 & - & - \\
Metric & $571.002(p<.001)$ & 65 & $134.900^{* *}$ & 16 & $.078(.072, .084)$ & 0.062 & 0.944 & 0.014 & 0.004 \\
Scalar & $1190.879(p<.001)$ & 49 & $619.877^{* *}$ & 16 & $.109(.103, .114)$ & 0.102 & 0.874 & 0.067 & 0.031 \\
Scalar (U.S. \& U.K.) & $287.001(p<.001)$ & 70 & $284.001^{* *}$ & 5 & $.070(.062, .079)$ & 0.062 & 0.96 & 0.016 & 0.008 \\
Scalar (U.S. \& Chinese) & $1032.196(p<.001)$ & 70 & $461.194^{* *}$ & 5 & $.120(.114, .127)$ & 0.112 & 0.824 & 0.120 & 0.042 \\
Scalar (U.K. \& Chinese) & $385.377(p<.001)$ & 70 & $185.625^{* *}$ & 5 & $.073(.066, .080)$ & 0.054 & 0.949 & 0.005 & 0.005 \\
\hline
\end{tabular}

$* * p<.001$ 


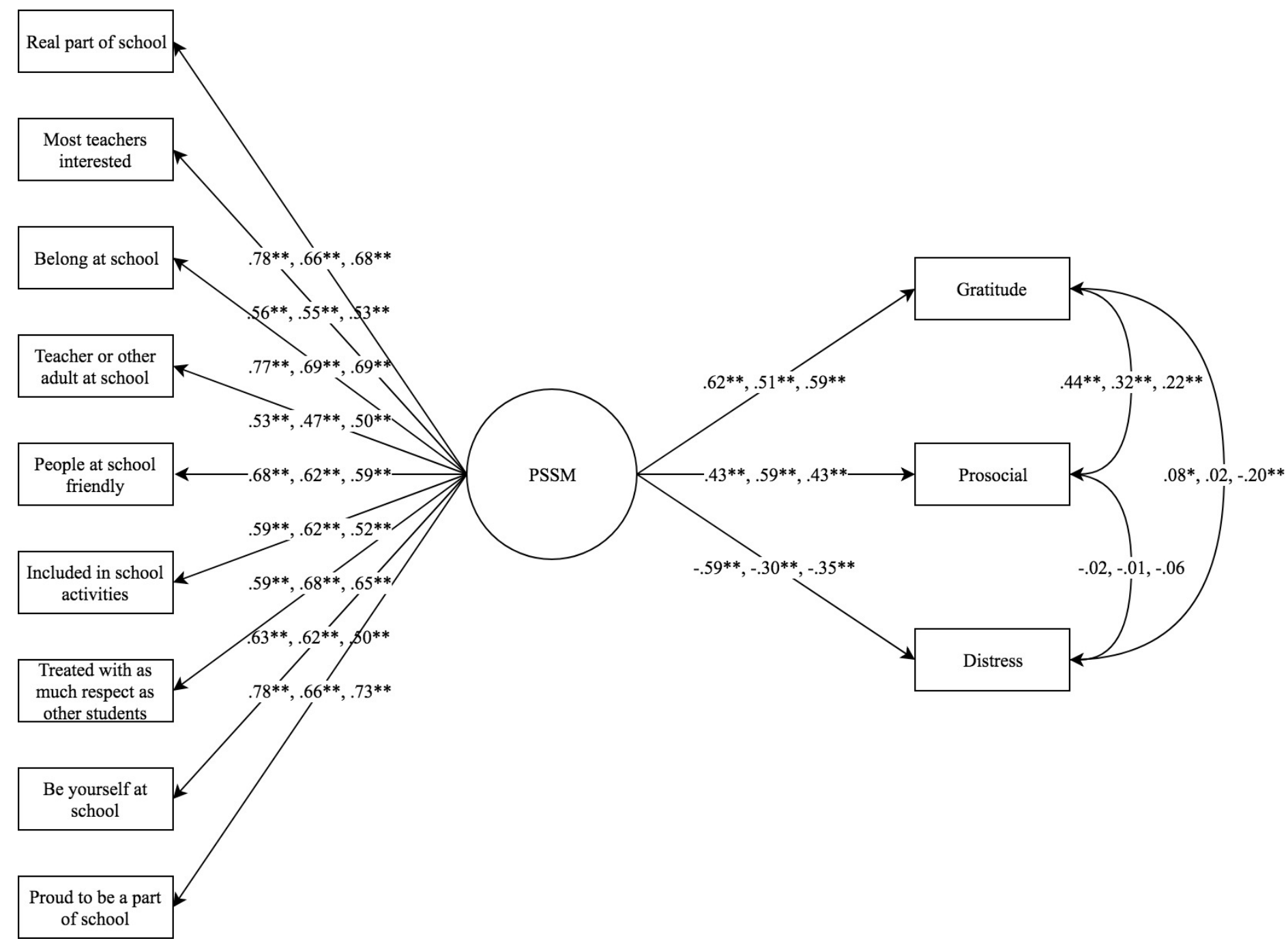

Figure 1. Psychological Sense of School Membership convergent and discriminant validity model for the U.S., Chinese, and U.K. samples, respectively. Path coefficients are completely standardized (path coefficients should be interpreted separately as full measurement invariance was not achieved across all three samples, $* p<.05$. $* * p<.001)$. 
SCHOOL BELONGING, United States, CHINA, United Kingdom.

\section{Preliminary Investigation of the Psychological Sense of School Membership Scale with Primary School Students in a Cross-Cultural} Context

Contact Information: Michael Furlong, mfurlong@ucsb.edu

\section{Online Supplementary Material}

\section{Description of Study Convergent Validity Measures}

Social and Emotional Health Survey - Primary (SEHS-P). Four gratitude items and four prosocial items from the SEHS-P were used in this study to assess convergent validity because of school belonging's positive association with gratitude (Froh et al., 2008) and prosocial behavior (Solomon et al., 1996). The SEHS-P is a 20-item strength-based measure developed by Furlong, You, Renshaw, O’Malley, and Rebelez (2013) for use by primary school students, Grades 4-6. Four gratitude items ("Do you feel thankful to go to your school?”... “Are you thankful when you get to learn new things at school?"... "Are you thankful to have nice teachers at your school?”... "Do you feel thankful that you have friends at your school?”) were combined to form one index. All three samples had adequate internal consistency: U.S. sample $(\alpha=.68)$, Chinese sample ( $\alpha=.69$ ), U.K. sample ( $\alpha=.69$ ). The four prosocial items ("Do you follow the classroom rules?”... "Do you follow the schoolyard rules?”... "Do you listen when your teacher is talking?”... “Are you nice to other students?") were also combined to form one index in the current study. All three samples had high internal consistency: U.S. sample ( $\alpha=.82)$, Chinese sample ( $\alpha=.81)$, U.K. sample ( $\alpha=.80$ ). The items used the same six-point response scale as the PSSM ( $1=$ no, never, $2=$ no, almost never, $3=$ yes, sometimes, $4=$ yes, often, $5=$ yes, very often, and 6 = yes, always).

Me and My School Questionnaire (M\&MS). For the U.S. and U.K. samples, the M\&MS (Deighton et al., 2013) was used as a measure of divergent validity because school belonging has been found to be inversely related to distress. The M\&MS is a 16-item self-report distress measure for use with children ages 8-12 years old. It has a 10-item emotional difficulties scale (e.g., "I feel lonely") and a six-item behavioral difficulties scale (e.g., "I break things on purpose") on a three-item response scale: never, sometimes, always. Deighton and colleagues (2013) found good internal consistency for the emotional difficulties and behavioral difficulties scales and high external validity. The measure was also found to have a two-factor solution in England: emotional difficulties and behavioral difficulties (Deighton et al., 2013). For this study, internal consistency for the U.S. sample ( $\alpha=.76)$ and the U.K. sample ( $\alpha=.77)$ were high, as measured by an overall M\&MS distress score, which was used in the path analyses. 
Strengths and Difficulties Questionnaire (SDQ). For the Chinese sample, the SDQ was used as a measure of divergent validity because it is also a measure of distress (Goodman, 1997). The Chinese sample completed the SDQ, a 25-item measure analyzing five scales: emotional symptoms, conduct problems, hyperactivity-inattention, peer problems, and prosocial behavior. Most studies have reported high internal consistency (Stone, Otten, Engels, Vermulst, \& Janssens, 2010) and support for the SDQ factor structure (Van Leeuwen, Meerschaert, Bosmans, De Medt, \& Braet, 2006), and results for measurement invariance show consistency across ethnicities (Niclasen, Skovgaard, Anderson, \& Somhovd, 2013). The SDQ uses a three-item response scale: not true, somewhat true, certainly true. The first four SDQ scales produce a total difficulties score (e.g., "I get very angry and often lose my temper”), indicating the severity of psychosocial problems. An overall SDQ total difficulties score was used in the current study's path analyses. The Chinese sample had high internal consistency for the SDQ total difficulties score (Cronbach’s $\alpha=.84$ ).

\section{Data Collection Procedures}

U.S. sample procedures. In the United States, data collection procedures were approved by the University of California Santa Barbara institutional review board. Students from seven schools in California completed the survey only when a parent or guardian gave signed consent. A student opt-out option was also included at the beginning of the online survey. The self-report survey, proctored by classroom teachers, was administered on school computers and tablets during fall 2016 and fall 2017. Items were presented in a random order with two items presented at a time on the screen using the Qualtrics ${ }^{\circledR}$ survey application. When a student did not respond to an item, they were prompted to give a response, but not required to respond. Student responses were filtered using three verification items to evaluate if they were able to read items and correctly fill in requested responses. Four percent of the sample was filtered out.

Chinese sample procedures. In China, a team of researchers from Hunan Normal University conducted data collection in five elementary schools between December 2016 and June 2017. Parents/guardians were provided with opt-out consent forms prior to the start of the study. In each school, four to seven classes were randomly selected and all students in each class were invited to participate in the study. Students completed a paper version of the survey that was administered during a selected class time. Graduate student researchers and teachers gave directions to the students and graduate student researchers were provided with a script to read to the students prior to competing the survey. The survey was read aloud to students who had difficulty with reading.

U.K. sample procedures. In the U.K., a team of researchers from the University of Roehampton collected data in three mainstream primary schools between February and June 2017. The protocol for this study was approved by the University's Research Ethics Committee. Opt-out consent forms were provided to the parents/guardians of all primary students within the three 
schools which participated in the study prior to the start of data collection. Students that participated in the study completed a paper version of the self-report survey during a selected class time. Graduate research assistants read instructions prior the completion of the questionnaires and provided support by reading aloud or answering queries to the students who were experiencing difficulties with reading.

\section{Exploratory Factor Analysis Results}

The initial EFA with all 18 items identified adequate fit for a two-factor solution, $\chi^{2}(118)=$ 290.49, $p<.01$; RMSEA = .06; SRMR = .09; CFI $=.92$. However, when examining the factor loadings, there were several items that cross-loaded and items that did not load strongly on either factor. Due to these inconsistencies, a parallel analysis was conducted, which supported a onefactor solution, indicating that the two-factor model did not fit best.

A series of EFAs were run following one-by-one item deletion based on low loadings and crossloadings (deletion of items 2, 3, 4, 14, 15, 18). Another EFA was run with the remaining 12 items, where only two items loaded onto the second factor (items 5 and 9) and both items were similar in wording (i.e., item 5 = “Are most teachers at your school interested in you?”; item $9=$ “Are teachers interested in students like you?”). Thus, one of these items was deleted to maximize measurement efficiency. Since the item 9 wording is more abstract, where students were asked to hypothesize about teacher's interest, it was deleted and item 5 was retained.

A subsequent EFA was run using the remaining 11 items, which generated good fit for a onefactor solution, $\chi^{2}(44)=99.95, p<.01$; RMSA $=.06$; SRMR $=.04$; CFI $=.95$. According to Howard's (2016) criteria, item 12 was deleted because it did not load well onto the factor structure. Another EFA was run using the remaining 10 items. A one-factor solution fit best and met fit index criteria, $\chi^{2}(35)=92.94, p<.01$; RMSEA $=.08$; SRMR $=.04$; CFI = .95. However, at this stage, only one negatively worded item remained and was distinctive from the other items: (i.e., item 16 = Do you wish you were in a different school?). In order to maintain an efficient and streamlined measure, this item was deleted so that the remaining survey items would include only positively worded items. This modification allowed the survey to measure a unidimensional positive construct of school belonging with nine items.

\section{References}

Deighton, J., Tymms, P., Vostanis, P., Belsky, J., Fonagy, P., Brown, A., ...Wolpert, M. (2013). The development of a school-based measure of child mental health. Journal of Psychoeducational Assessment, 31, 247-257. doi:10.1177/0734282912465570

Froh, J. J., Sefick, W. J., \& Emons, R. A. (2008). Counting blessings in early adolescents: An experimental study of gratitude and subjective well-being. Journal of School Psychology, 46, 213-233. doi:10.1016/j.jsp.2007.03.005 
Furlong, M. J., You, S., Renshaw, T. L., O’Malley, M. D., \& Rebelez, J. (2013). Preliminary development of the Positive Experiences at School Scale for elementary school children. Child Indicators Research, 6, 753-775. doi:10.1007/s12187-013-9193-7

Niclasen, J., Skovgaard, A. M., Andersen, A. N., Somhovd, M. J., \& Obel, C. (2013). A confirmatory approach to examining the factor structure of the strengths and difficulties questionnaire (SDQ): A large scale cohort study. Journal of Abnormal Child Psychology, 41, 355-365. doi:10.1007/s10802-012-9683-y

Solomon, D., Battisch, V., Kim, D., \& Watson, M. (1996). Teacher practices associated with students' sense of classroom as a community. Social Psychology of Education, 1, 235-267. doi:10.1007/BF02339892

Stone, L. L., Otten, R., Engels, R. C., Vermulst, A. A., \& Jansses, J. M. (2010). Psychometric properties of the parent and teacher versions of the Strengths and Difficulties Questionnaire for 4- to 12year-olds: A review. Clinical Child and Family Psychology Review, 12, 254-274. doi:10.1007/s10567-010-0071-2

Van Leeuwen, K., Meerschaert, T., Bosmans, G., De Medts, L., \& Braet, C. (2006). The strengths and difficulties questionnaire in a community sample of young children in Flanders. European Journal of Psychological Assessment, 22, 189-197. doi:10.1027/1015-5759.22.3.189 
Psychological Sense of School Membership (PSSM) Scale Items Modified in Question Format for Primary School Grade Students

\footnotetext{
1. Do you feel like a real part of your school?*

你 $\square$ 得你是学校真正的一 $\square \square$ ?

2. Do people at your school notice when you are good at something?

当你擅 $\square$ 某些事情 $\square$, 学校里的人会注意到 $\square$ ?

3. Is it hard for students like you to be socially accepted at school? 在学校里, 像你 $\square \square$ 的学生在人 $\square$ 交往中会 $\square$ 以被他人接受 $\square$ ?

4. Do other students at your school think you have good ideas?

学校里的其他同学 $\square \square$ 你有好主意 $\square$ ?
}

5. Are most teachers at your school interested in you?* 学校里的大部分老 $\square$ 关注你 $\square$ ?

6. Do you belong at your school?*

你 $\square$ 得你属于你的学校 $\square$ ?

7. Is there a teacher or some other adult at school you can talk to if you have a problem?* 当你有困 $\square$ 的 $\square$ 候，你可以跟学校里的老 $\square$ 或其他成年人 $\square \square \square$ ?

8. Are people at school friendly to you?* 学校里的人 $\square$ 你友好 $\square$ ?

9. Are teachers interested in students like you?

老 $\square \square$ 关注像你 $\square \square$ 的学生 $\square$ ?

10. Are you included in a lot of school activities?*

$\square$ 人会邀 $\square$ 你参与学校的很多活 $\square$

11. Are you treated with as much respect as other students?* 你受到跟其他同学一 $\square$ 的尊重 $\square$ ?

12. Do you feel that you are different from other students at your school?

你 $\square$ 得你和学校里的其他同学不同 $\square$ ?

13. Can you be yourself at school?* 你能在学校里做你自己 $\square$ ?

14. Do teachers respect you?

老 $\square$ 尊重你 $\square$ ?

15. Do people at school know you can do good work? 有老 $\square$ 和同学 $\square$ 知道你能做好很多事情 $\square$ ?

16. Do you wish you were in a different school? 你希望自己是在另一所学校就 $\square \square$ ?

17. Are you proud to be a part of your school?* 你 $\square$ 自己是学校的一 $\square$ 感到 $\square$ 傲 $\square$ ?

18. Do other students accept you just the way you are? 其他同学接受 $\square \square$ 的你 $\square$ ?

Note. $\left(^{*}\right)$ indicates the final items retained in the study. 